\title{
Atividades Interativas para o Ensino de Ciências em Ambientes Mediados por Tecnologia
}

\author{
Nelson Bezerra Jacinto Júnior ${ }^{1,2}$, José Luiz de Souza Pio ${ }^{1}$ \\ ${ }^{1}$ Instituto de Computação - Universidade Federal do Amazonas (UFAM) \\ Av. Gen. Rodrigo O. J. Ramos, 3000 - Campus Universitário - Manaus, AM - Brasil \\ ${ }^{2}$ Secretaria de Estado de Educação do Amazonas (SEDUC) \\ Centro de Mídias de Educação do Amazonas (CEMEAM) \\ Rua Waldomiro Lustoza, 250 - Japiim II - Manaus, AM - Brasil \\ nelson.bezerra@seducam.pro.br, josepiodicomp.ufam.edu.br
}

\begin{abstract}
This work aims the development of a didactic-pedagogical methodology based on interactive activities to technology-mediated teaching environments. The methodology is based on interactive activities that are integrated through information and communication technologies. The methodological process was applied with the content of Physics in second year high school classes in five schools in city of Manacapuru/Am. The results indicate improvements in the structure of the methodology and method readjustment used in teaching with technological mediation offered by the Amazonas Educational System.
\end{abstract}

Resumo. O objetivo deste trabalho é desenvolver uma metodologia didáticopedagógica baseada em atividades interativas em ambientes de ensino mediados por tecnologia. A metodologia consiste em uma estrutura educativa baseada em atividades interativas que se integram por meio das tecnologias de informação e comunicação. O processo metodológico foi aplicado com o conteúdo de Física em turmas do $2^{\circ}$ ano do ensino médio de cinco escolas do município de Manacapuru/Am. Os resultados sinalizam melhorias na estrutura da metodologia, além de servir para uma melhor readequação dos métodos utilizados no ensino com mediação tecnológica ofertada pelo Sistema Educacional do Amazonas.

\section{Introdução}

O Estado do Amazonas possui uma área perto de 1,6 milhões de $\mathrm{Km}^{2}$, ocupando cerca de $1 / 5$ do território nacional, capilarizada pela maior malha hidroviária do mundo, formada por mais de mil rios. Nessa imensa região vivem cerca de quatro milhões de pessoas, das quais dois milhões estão instaladas na capital Manaus e os outros dois milhões estão espalhados pelos 61 municípios interioranos, em mais de seis mil comunidades, numa densidade demográfica de 2,5 habitantes por $K \mathrm{~m}^{2}$, segundo os dados do IBGE. Essas informações monstram o quanto é difícil levar a educação formal aos habitantes residentes nas comunidades rurais dos municípios, principalmente àquelas de difícil acesso. Completando o quadro de dificuldades tem-se que observar ainda a sazonalidade com extremos de enchente e vazante dos rios e a precariedade de energia elétrica em cerca de $30 \%$ dessas comunidades. 
VII Congresso Brasileiro de Informática na Educação (CBIE 2018)

Anais do XXIX Simpósio Brasileiro de Informática na Educação (SBIE 2018)

Para vencer todas essas dificuldades e com o objetivo inicial de oferecer Ensino Médio aos interioranos, o Governo do Estado do Amazonas criou, em junho de 2007, o Centro de Mídias de Educação do Amazonas (CEMEAM). No CEMEAM, uma Central de Produção Educativa para TV transmite diariamente aulas ao vivo para todo o interior, por meio de TV interativa por IP (IPTV), conectada através de uma rede de satélite VSAT bidirecionais, o que permite a interatividade entre as salas de aula. Cada sala de aula possui além da antena, um kit tecnológico, que inclui computador, impressora, webcam, microfone, telefone IP, modem, rádio, nobreak e um televisor LCD de 42 polegadas. O acesso à Internet está disponível em todas as salas.

Os sistemas de ensino a distância como o CEMEAM e os seus respectivos ambientes tecnológicos oferecem aos estudantes e professores um meio que viabiliza o acesso mais fácil e rápido ao conhecimento. Favorecem ainda a construção, integração, a interatividade e a difusão das ideias e soluções. Por outro lado, o uso dessas mesmas TIC no campo do ensino de Ciências, requer novos meios de ensinar, de aprender e de desenvolver processos didáticos adequados a essas novas demandas tecnológicas, complexas e com uma diversidade de formas e tipos de representação do conhecimento.

O objetivo deste trabalho é integrar um conjunto de atividades interativas para ensino de Ciências, contextualizada na disciplina de Física, aos ambientes de ensino a distância mediados por tecnologia, associando as potencialidades tecnológicas com o domínio dos processos pedagógicos.

A aprendizagem por meio de atividades interativas tem sido um tema frequente em vários trabalhos [Castro and de Menezes 2011, Gadelha and Castro 2017, Sobrinho et al. 2016, Salgado et al. 2013]. No entanto, a integração dessa forma de aprendizagem aos ambientes de tecnológicos e as novas TIC apresenta-se como problemas desafiadores para a pesquisa científica em Ensino de Ciências [Barbato et al. 2017, Santos et al. 2017, Garcia and Direne 2013].

$\mathrm{Na}$ abordagem desenvolvida neste trabalho, as atividades interativas são planejadas pelo professor ministrante, o especialista na disciplina, que integra as atividades com os procedimentos didáticos-pedagógicos. Os alunos são orientados pelo professor ministrante e pelo professor presencial a desenvolverem essas atividades em grupos na própria sala de aula, de tal forma que os grupos de uma mesma sala de aula possam compartilhar suas dúvidas e soluções entre eles e também a interagirem com grupos de outras salas de aula de localidades ou comunidades diferentes do mesmo município ou de municípios diferentes. A interação entre comunidades diferentes se dá através de um chat público e/ou privado e também através de videoconferência que ocorre em um momento específico da aula chamado de interatividade. Tanto o chat como a interatividade acontece em tempo real com transmissão ao vivo pelo IPTV. Na interatividade feita por videoconferência os alunos compartilham suas respostas com o professor ministrante e com outras comunidades.

Segundo [Garcia and Direne 2013], com a inclusão da tecnologia na educação o desafio é concentrar-se na criação de novas formas de aprendizagem baseadas na utilização de diversos tipos de ferramentas interativas. Então, têm-se várias ferramentas aplicáveis no campo educação em ambientes mediados por tecnologia, mas com importantes lacunas em relação a uma estrutura metodológica guia sobre como planejá-las, de 
VII Congresso Brasileiro de Informática na Educação (CBIE 2018)

Anais do XXIX Simpósio Brasileiro de Informática na Educação (SBIE 2018)

acordo com a estrutura curricular de cada área do conhecimento. Nesse contexto, a abordagem desenvolvida viabiliza o uso de ferramentas tecnológicas para auxiliar a interação em tempo real entre grupos de alunos de comunidades diferentes e de como aplicá-las visando melhorias significativas no processo de ensino-aprendizagem.

As atividades interativas podem proporcionar aos alunos um desenvolvimento cognitivo mais aprimorado quando estes estão inseridos num contexto social coletivo de aprendizagem. No início do século passado o psicólogo russo Lev Vygotsky criou e definiu um conceito conhecido como zona de desenvolvimento proximal (ZDP), caracterizado como a distância entre o nível de desenvolvimento real, determinado pela resolução independente de problemas, e o nível superior de desenvolvimento potencial, determinado pela resolução de problemas sob orientação de um adulto ou em colaboração com pares mais capazes [Vygotsky 1980]. O processo de aprendizagem está ligado ao convívio social dos indivíduos, portanto, a interação entre pares, com auxílio de um mediador (professor).

Para [Levy 2010] a interação no ciberespaço é como a expressão da aspiração de construção de um laço social, que não seria fundado nem sobre links territoriais, nem sobre relações institucionais, nem sobre as relações de poder, mas sobre a reunião em torno de centros de interesses comuns.

Ainda segundo [Levy 2010], as atividades interativas representam uma perspectiva promissora para o desenvolvimento cognitivo do aluno envolvido no processo ensino aprendizagem. Isso significa que quanto mais o aluno se envolve com determinado conjunto de informações, mais fácil fica para essa informação ser lembrada posteriormente. Portanto a diversidade de atividades deve ser proposta pelos educadores de tal forma que o aluno possa interagir colaborativamente com seus pares com o objetivo de uma maior interação social entre eles gerando um espirito de colaboração, autonomia e melhor aprendizado.

O processo metodológico foi avaliado por meio de um estudo de caso realizado com turmas do ensino médio das escolas estaduais do município de Manacapuru (cidade situada as margens do Rio Solimões, a $93 \mathrm{~km}$ de Manaus, a capital amazonense), vinculadas ao ensino com mediação tecnológica oferecida pelo Centro de Mídias de Educação do Amazonas, CEMEAM. O conteúdo desenvolvido nessas atividades foi referente à disciplina de Física, relativo ao $2^{\circ}$ ano do ensino médio, ministrados na Unidade I da referida disciplina. De forma mais específica foram a termometria, termologia e calorimetria. A principal contribuição do trabalho é o desenvolvimento de uma metodologia integradora e flexível para o ensino de Ciências.

\section{Trabalhos Relacionados}

Os principais trabalhos desenvolvidos nos últimos anos mostram como são realizadas as atividades interativas na prática, com a utilização das ferramentas de interação como chats, fóruns e videoconferência. Em geral os trabalhos não apresentam ou desenvolvem uma metodologia didático-pedagógica que possa integrar as atividades interativas às ferramentas utilizadas e as características da formação dos grupos de alunos por suas características e competências.

[Costa 2014] abordou o tema das tecnologias utilizadas no processo de ensinoaprendizagem enfatizando a importância do uso das tecnologias de comunicação, princi- 
VII Congresso Brasileiro de Informática na Educação (CBIE 2018)

Anais do XXIX Simpósio Brasileiro de Informática na Educação (SBIE 2018)

palmente com o advento da internet, e, como estas colaboram para uma formação mais completa do aluno e permitem que se tenha um grande desenvolvimento da educação à distância. Porém, não apontou como as tecnologias de comunicação e ferramentas interativas se integram com o uso da Internet.

[Torres and Irala 2014] observaram as atividades interativas no contexto da aprendizagem colaborativa. Os autores fizeram um contraponto entre a aprendizagem colaborativa e cooperativa, estabelecendo diferenças significativas entre elas. Descreveram detalhadamente como a aprendizagem cooperativa se desenvolveu através da história. Uma interessante cronologia envolvendo vários autores e teóricos que realizaram vários trabalhos relacionados com as atividades cooperativas. O conceito de aprendizagem colaborativa é exposto de forma bastante simples,como uma situação de aprendizagem na qual duas ou mais pessoas aprendem ou tentam aprender algo juntas.

Já [Barbato and Caixeta 2014], utilizaram a plataforma moodle e um fórum de discussão para que alunos do ensino superior comentassem sobre a aplicação, por um professor de matemática do ensino médio, de uma prova com cinco questões. As postagens dos alunos caracterizavam atividades interativas e colaborativas. Está claro o uso de uma ferramenta interativa no trabalho, mas ficou restrito a apenas o fórum de discussão.

O trabalho de [Sullivan et al. 2015] explorou as atividades interativas em uma perspectiva diferente, onde o professor não é especialista da área de ensino, ou seja, não desempenha em sua totalidade um papel de mediador do processo. O estudo analisou a forma como os alunos gostariam de serem ensinados, como eles ensinariam seus pares se tivessem a oportunidade e se eles realmente aprendem o conteúdo do currículo usando essa abordagem. A pesquisa utilizou uma metodologia exploratória de estudo de caso. Os resultados sugeriram que os estudantes desejam variadas experiências de aprendizagem que incluem muitos dos elementos que se enquadram na realidade da aprendizagem do século XXI, que com algum apoio e encorajamento podem criar experiências inovadoras de aprendizagem para seus pares e que eles possam aprender o conteúdo curricular durante processo de ensino aprendizagem.

No contexto deste trabalho, se desenvolveu e se analisou uma metodologia diferenciada, objetivando que os alunos aprendam o conteúdo por meio de atividades interativas, desafiadoras e inovadoras, utilizando ferramentas tecnológicas aplicadas em um ambiente mediado por tecnologia com interatividade entre os alunos em tempo real através dessas ferramentas.

\section{Metodologia}

O processo metodológico está dividido em quatro etapas principais que dialogam entre si, ao mesmo tempo em que formam uma relação de interdependência e se integram para a formação da abordagem. A Figura 1 mostra o desenho esquemático da metodologia. Cada etapa está descrita em seguida.

A primeira etapa contempla o planejamento das atividades interativas a serem desenvolvidas pelos grupos de alunos e ainda pela escolha das ferramentas tecnológicas a serem utilizadas no desenvolvimento das atividades planejadas. Essa etapa é de responsabilidade do professor ministrante, especialista da área do conhecimento da disciplina ministrada. 
VII Congresso Brasileiro de Informática na Educação (CBIE 2018)

Anais do XXIX Simpósio Brasileiro de Informática na Educação (SBIE 2018)

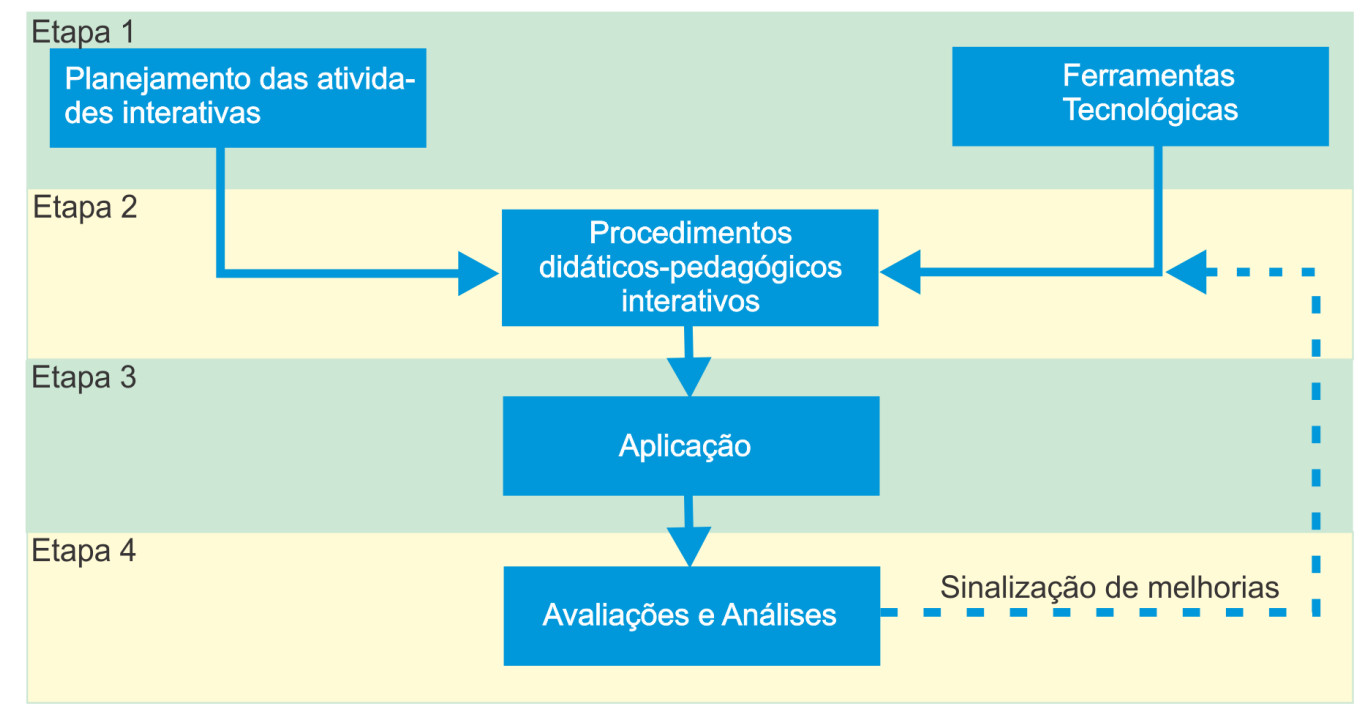

Figura 1. Desenho esquemático da dinâmica metodológica. A linha tracejada representa a retroalimentação para a melhoria do processo.

A segunda etapa refere-se aos procedimentos didático-pedagógicos de caráter interativo que estão integrados com a etapa um. O professor ministrante também é responsável por está fase.

$\mathrm{Na}$ terceira etapa, as atividades planejadas e seus procedimentos serão aplicados aos grupos de alunos que serão formados levando-se em conta suas competências. Nesta etapa o professor presencial é o responsável pela escolha dos alunos, por estar diariamente envolvido com os eles, esse conhecimento sobre os alunos, suas capacidades e habilidades, facilita a formação dos grupos e a aplicação das atividades interativas previamente planejadas nas etapas anteriores.

Na quarta etapa acontecerá a avaliação do processo e a análise dos dados obtidos. Esses resultados poderão serem usados para a reformulação dos procedimentos didáticopedagógicos. Esta fase é novamente de responsabilidade do professor ministrante.

\section{Aplicações Experimentais e Resultados}

A proposta metodológica foi aplicada aos alunos do segundo ano do ensino médio, regularmente matriculados, no turno noturno de cinco escolas do município de Manacapuru/Am. Cada escola oferece à população ensino fundamental e/ou médio. As turmas de ensino médio, dessas escolas possuem cerca de 10 a 30 alunos matriculados regularmente e conta com um professor presencial responsável pelas atividades pedagógicas diárias, manuseio e manutenção do kit tecnológico usado para exibição, ao vivo, das aulas transmitidas diariamente pelo CEMEAM. A Figura 2 mostra a fotografia de duas das cinco escolas escolhidas para a aplicação da metodologia.

Em cada turma foram formados grupos, orientados pelo professor presencial, com no máximo quatro alunos (ver Figura 3), para o desenvolvimento das atividades planejadas pelo professor ministrante e aplicadas durante a dinâmica local interativa (DLI). Cada DLI tem a duração de quinze minutos. Os grupos desenvolveram as atividades e compartilharam seus resultados entre si, com os grupos da mesma turma e por meio do chat com os grupos de outras turmas localizadas em outras escolas. 
VII Congresso Brasileiro de Informática na Educação (CBIE 2018)

Anais do XXIX Simpósio Brasileiro de Informática na Educação (SBIE 2018)

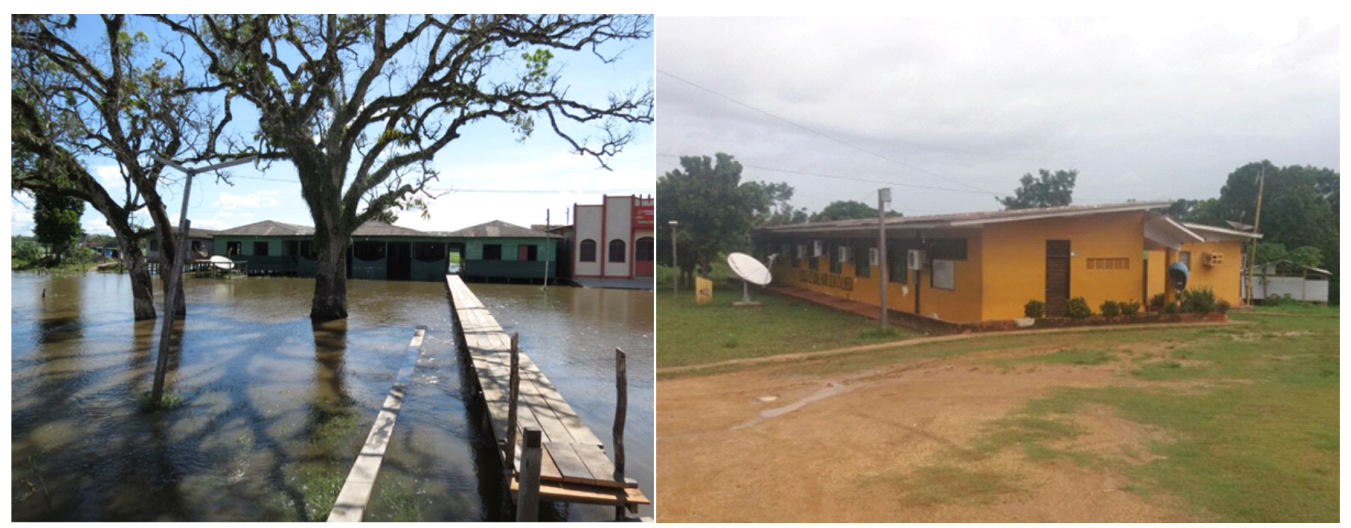

Figura 2. Escolas escolhidas. Nota-se à esquerda a alagação devido a enchente do rio Solimões e presença das antenas de satélite em ambas as imagens.

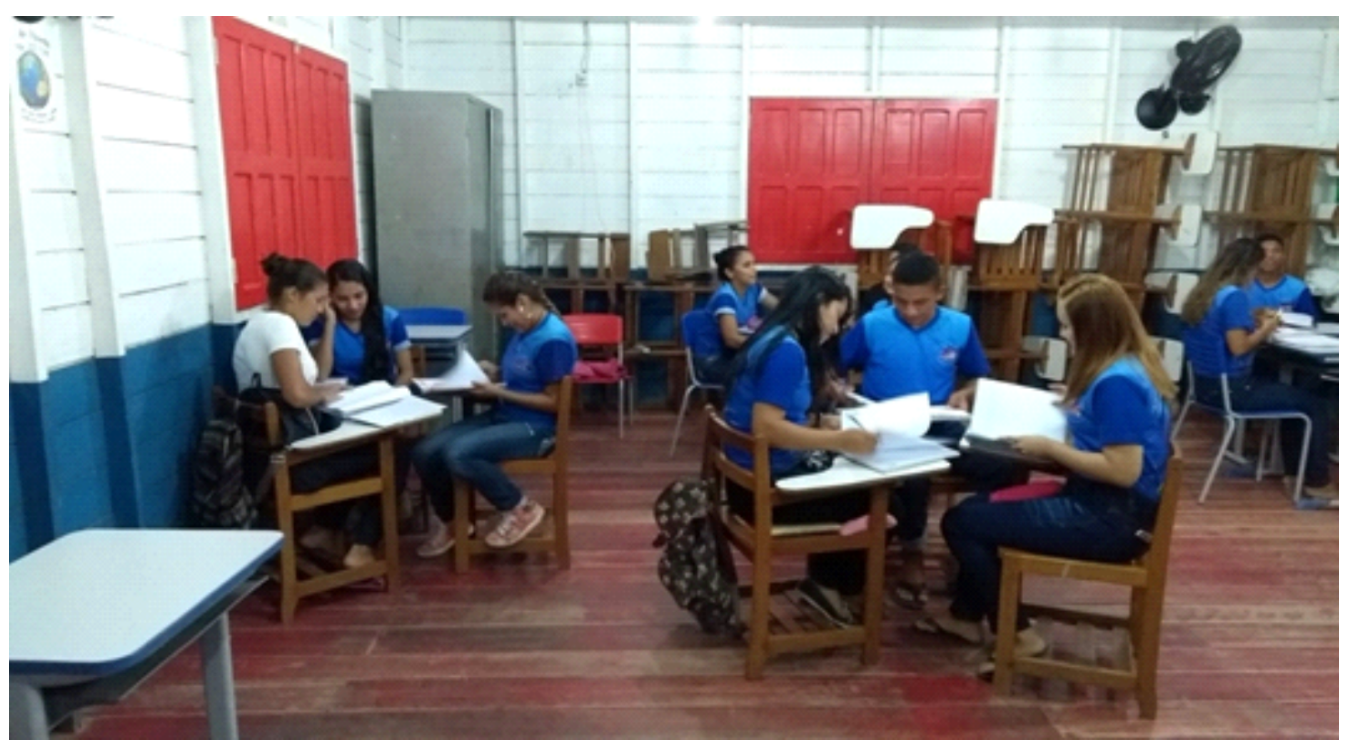

Figura 3. Grupos de alunos em atividade na sala de aula.

Após a realização das atividades os resultados também foram compartilhados através de videoconferência, no momento da interatividade, momento este parte integrante da metodologia empregada pelo CEMEAM que acontece, com a participação de todas as turmas e do professor ministrante, através de transmissão ao vivo realizada pelo IPTV.

\subsection{Experimentos}

O experimento foi constituído por dez atividades interativas aplicadas simultaneamente aos grupos de alunos das cinco escolas participantes da pesquisa. Em cada dia de aula os alunos resolviam duas atividades, cada uma com duração de 15 minutos, durante a DLI, totalizando cinco dias de duração de aplicações experimentais. Para cada atividade foi feito o planejamento e o desenvolvimento de acordo com a metodologia proposta.

\subsection{Análise dos Questionários}

O questionário aplicado aos alunos constava de seis questões e pode ser acessado pelo endereço eletrônico https : / / goo.gl / forms / uf 0c40VbEnehh8IX2, sendo 
VII Congresso Brasileiro de Informática na Educação (CBIE 2018)

Anais do XXIX Simpósio Brasileiro de Informática na Educação (SBIE 2018)

a primeira questão com relação à idade de cada aluno participante da pesquisa. A finalidade dessa pergunta é estabelecer uma relação entre a idade considerada ideal para cursar o segundo ano do ensino médio e a idade real dos alunos participantes. A grande maioria dos alunos participantes da pesquisa está na faixa etária entre 15 e 20 anos de idade. De forma mais detalhada tem-se um aluno com quinze anos $(1,3 \%)$, vinte e um alunos com dezesseis anos $(26,9 \%)$, vinte alunos com dezessete anos $(25,6 \%)$, dez alunos com dezoito anos $(12,8 \%)$ e seis alunos com dezenove anos de idade $(7,7 \%)$. Os resultados mostraram que o as condições para o aprendizado dos alunos pesquisados é bastante favorável, já que em sua maioria, os estudantes então dentro da faixa etária ideal para o segundo ano do ensino médio.

A segunda questão diz respeito à metodologia interativa aplicada durante a dinâmica local interativa. Questionou-se se a metodologia interativa utilizada para a realização das atividades propostas na DLI facilitam a resolução das mesmas? Como possíveis respostas o aluno tinha três alternativas: sim, não ou em parte, tornando a pergunta de caráter fechado. A Figura 4 (a) mostra que a grande maioria dos estudantes, na verdade $91 \%$ deles, respondeu que a metodologia colaborativa aplicada para resolução das atividades propostas, durante a Dinâmica Local Interativa, facilitou a resolução das mesmas. Esse resultado confirma vários outros estudos sobre as vantagens que uma metodologia colaborativa pode trazer aos estudantes no processo ensino aprendizagem. Dessa forma conclui-se que, trabalhando em grupo, de forma interativa, trocando ideias e experiências entre si, os alunos obtiveram melhores resultados na realização das atividades propostas.

A terceira questão proposta aos alunos no questionário da pesquisa, se refere à compreensão dos conteúdos abordados pelas atividades propostas durante a DLI. Questionou-se se o aprendizado do conteúdo, proposto nas atividades interativas, foi facilitado pela metodologia empregada? Assim como ocorreu na primeira questão o alunos escolheram entre as três opções possíveis de resposta. Os resultados foram registrados e representados de forma gráfica na Figura 4 (b). Uma quantidade expressiva de estudantes, $89,7 \%$ deles, assimilou melhor o conteúdo abordado nas atividades propostas com o uso da metodologia participativa, enquanto apenas 10,3\% assimilou em parte.

A quarta questão tratou das ferramentas tecnológicas associadas à metodologia interativa. Questionou-se se as ferramentas tecnológicas utilizadas contribuíram para um melhor aprendizado dos conteúdos e facilitaram a resolução das atividades interativas propostas na DLI? Do total de 70 alunos, ou $89,7 \%$, responderam sim à pergunta descrita acima. Apenas oito alunos, 10,3\% do total, acreditam que o uso dessas ferramentas colabora em parte com o aprendizado e na solução das atividades propostas (Figura 4 (c)). Nenhum dos alunos pesquisados respondeu não à pergunta mostrando que todos, de alguma forma, tiveram um melhor aproveitamento com o uso das ferramentas tecnológicas utilizadas durante o desenvolvimento das atividades.

A quinta questão trata das contribuições que a utilização do chat e vídeo conferência trazem para a aprendizagem dos estudantes. Questionou-se se o uso do chat e da videoconferência para compartilhar os resultados e dúvidas existentes nas atividades contribuíram para um melhor aprendizado do conteúdo? Nenhum dos estudante respondeu que o uso do chat e videoconferência não contribuem para um melhor aprendizado dos conteúdos relacionados com as atividades desenvolvidas durante a DLI. Somente 10,7\% 
VII Congresso Brasileiro de Informática na Educação (CBIE 2018)

Anais do XXIX Simpósio Brasileiro de Informática na Educação (SBIE 2018)

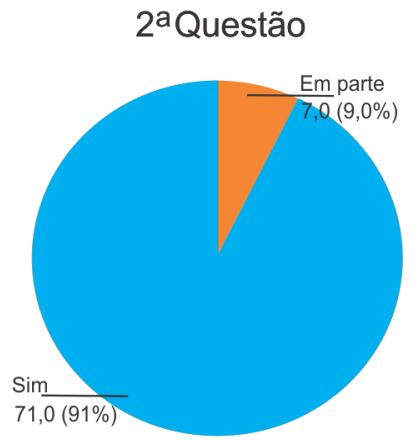

(a)

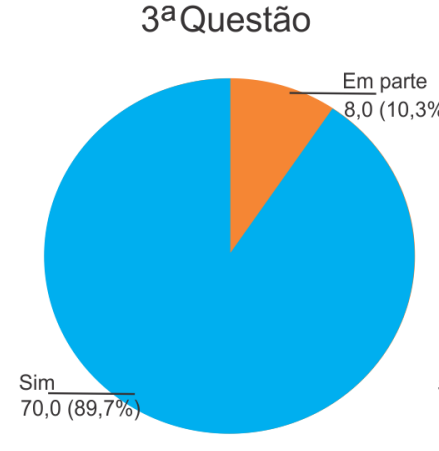

(b)

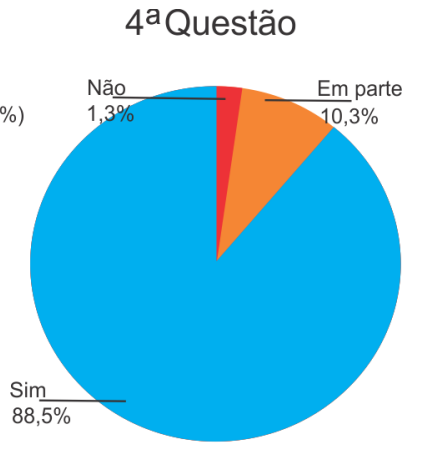

(c)

Figura 4. Distribuição das respostas dos estudantes em relação às questões sobre a metodologia ( $2^{a}$ questão), compreensão dos conteúdos ( $3^{a}$ questão) e ferramentas tecnológicas ( $4^{a}$ questão).

dos alunos consideraram que a contribuição era parcial. Esses resultados estão mostrados no gráfico da Figura 5 (a). Os estudantes mais capazes ou com mais competência auxiliaram os outros no desenvolvimento das atividades, dessa maneira se dá o processo de colaboração entre os pares.

A última pergunta do questionário teve como objetivo promover um contraponto, uma comparação entre as atividades desenvolvidas pelos estudantes com o uso da metodologia aplicada para a resolução das atividades de forma interativa e àquelas que utilizam uma proposta metodológica diferente.A Figura 5 (b) mostra que a maioria dos participantes, $85,9 \%$ concordam que a metodologia empregada facilitou o aprendizado dos conteúdos e a resolução das atividades, quando comparada com outras metodologias empregadas anteriormente. Uma parcela correspondente a $10,3 \%$ do total de alunos respondeu que não houve diferença.

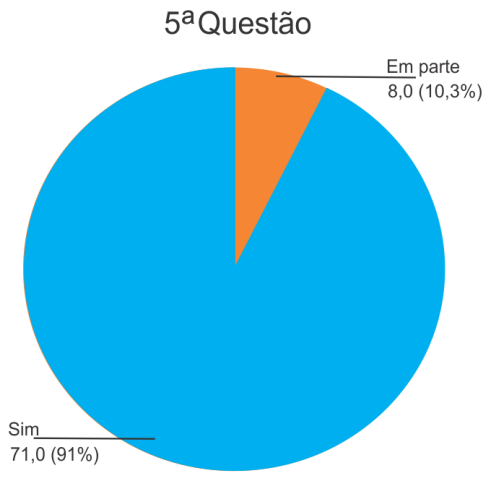

(a)

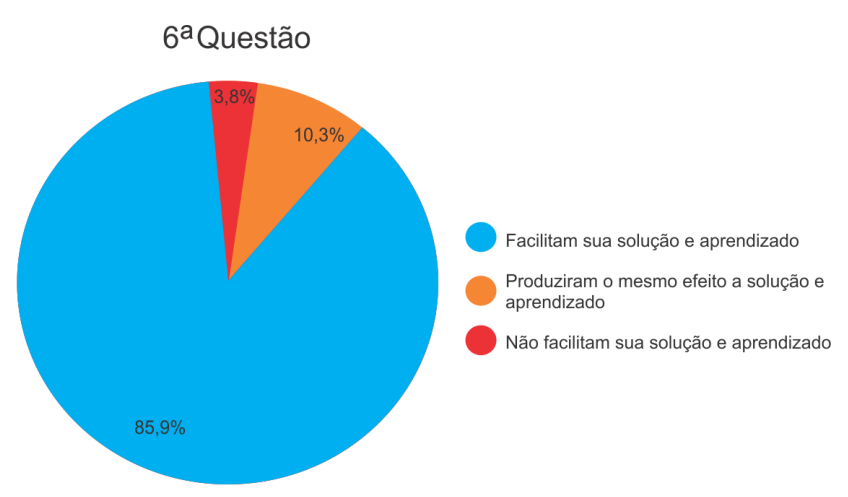

(b)

Figura 5. Distribuição das respostas dos estudantes em relação às questões sobre a contribuição das ferramentas interativas ( $5^{a}$ questão) e a comparação entre metodologias ( $6^{a}$ questão).

Por fim, foi solicitada uma auto-avaliação dos alunos. A maioria, $69,2 \%$ dos estudantes, se auto avaliou com um ótimo rendimento. Isso significa que esses estudantes consideram que aproveitaram muito as práticas aplicadas no experimento com a utilização da proposta metodológica e se sentiram capazes de desenvolver as atividades de uma forma bastante satisfatória. Os dados representados pelo gráfico da Figura 5 (b) revelam que a 
VII Congresso Brasileiro de Informática na Educação (CBIE 2018)

Anais do XXIX Simpósio Brasileiro de Informática na Educação (SBIE 2018)

maioria dos estudantes que participaram da pesquisa, 85,9\% dos participantes, concordam que a metodologia empregada facilitou o aprendizado dos conteúdos e facilitou a resolução das atividades, quando comparada com outras metodologias empregadas anteriormente. Uma parcela correspondente a 10,3\% do total de alunos respondeu que não houve diferença com relação ao aprendizado. Estes resultados estão espelhados na Figura 6

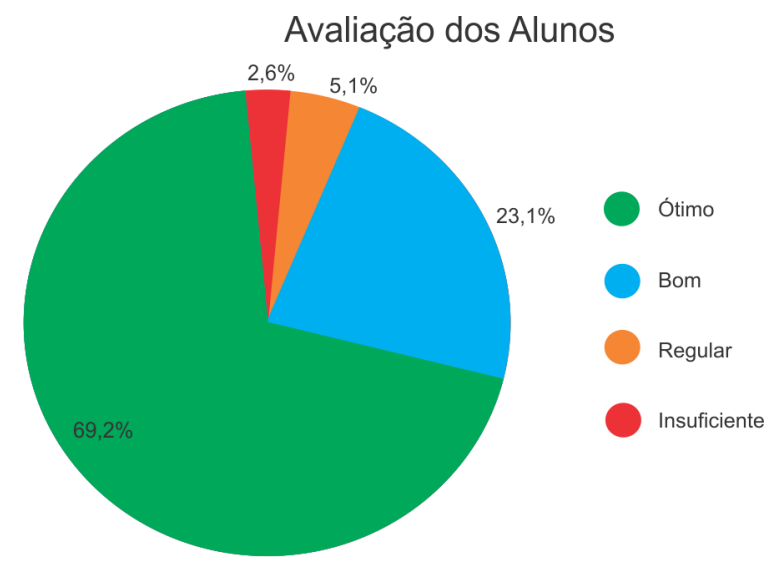

Figura 6. Distribuição da auto-avaliação dos alunos.

Os professores presenciais foram submetidos a uma entrevista por meio da qual se pode comprovar que a proposta metodológica aplicada é proveitosa e que esse processo pode levar efetivamente ao aprendizado cooperativo. Portanto esses resultados corroboram as opiniões dos alunos sobre a eficácia da proposta utilizada, assim toma-se como bem sucedida a série de experimentos realizada para a aplicação das atividades e posterior coleta de dados, mostrando que a proposta metodológica é válida para ser utilizada para o ensino de Ciências e até mesmo em outras áreas do conhecimento.

\section{Conclusões}

A proposta metodológica desenvolvida neste trabalho visou a aplicação de atividades interativas no ensino de Ciências em ambientes de ensino a distância mediados por tecnologia. Os resultados obtidos após a aplicação da metodologia em turmas de Física do ensino médio em escolas do Município de Manacapuru/Am, mostraram a eficiência e funcionalidade desta abordagem. As atividades interativas aplicadas durante os experimentos proporcionaram aos estudantes a utilização de competências e a aquisição habilidades a fim de se chegar a um objetivo comum definido pelo planejamento. As estratégias para aplicação e desenvolvimento das atividades figuraram como parte importante da estruturação dos planos de ensino, já que a utilização de uma estratégia adequada às características da atividade desenvolvida também contribuiu para aumentar as possibilidades de aprendizado dos estudantes.

Como trabalhos futuros irá se buscar intensificar o uso de aparelhos celulares integrados à plataforma tecnológica. A criação de aplicativos para celulares ou smartphones que permitissem o compartilhamento de respostas, cálculos, dúvidas e comentários criando grupos de estudo colaborativos. Também se buscará maior diversificação do processo avaliativo no que se refere ao rendimento dos alunos por meio de avaliações quantitativas, antes e depois da aplicação da metodologia, para se estabelecer padrões e 
VII Congresso Brasileiro de Informática na Educação (CBIE 2018)

Anais do XXIX Simpósio Brasileiro de Informática na Educação (SBIE 2018)

parâmetros estatísticos que permitam comparar os rendimentos com e sem a utilização da metodologia.

\section{Referências}

Barbato, C. N., Bortoletto, M. L., and Neto, S. P. (2017). Utilização de metodologias ativas no ensino de cálculo numérico - relato de uma experiência. Innovando en Eeducación Superior: Experiencias Clave en Latinoamérica y el Caribe 2016-2017., pages 79-84.

Barbato, S. and Caixeta, J. E. (2014). Novas tecnologias e mediação do conhecimento em atividades colaborativas no ensino superior. Linhas Críticas, 20(42).

Castro, A. and de Menezes, C. S. (2011). Aprendizagem colaborativa com suporte computacional. Pimentel, M. e Fuks, H. Sistemas Colaborativos. Rio de Janeiro: Campus. ISBN, pages $978-85$.

Costa, A. F. (2014). Ambiente colaborativo de ensino/aprendizagem para o ensino fundamental baseado nos princípios da web semântica. Dissertação de mestrado (mestrado em ciência da computação), Universidade Federal de Góiais.

Gadelha, B. and Castro, A. (2017). A reference model for teaching collaborative mobile systems. In Proceedings of the 31st Brazilian Symposium on Software Engineering, pages 374-383. ACM.

Garcia, L. F. U. and Direne, A. (2013). Metodologia para implementação de estratégias colaborativas mediadas por ferramentas de interação síncrona. Tecnologias, Sociedade e Conhecimento, 1(1):80-99.

Levy, P. (2010). Cibercultura. Editora 34.

Salgado, N., Castro, T., and Castro, A. (2013). Aprendizagem colaborativa de programação com scratch e opensimulator. In Proceedings of the X Brazilian Symposium in Collaborative Systems, page 104. Sociedade Brasileira de Computação.

Santos, G., Maffezzolli, A. P., and ao, A. G. (2017). O uso da tecnologia de informação e comunicação - tic na formação inicial de professores de uma instituição de ensino superior no municÃpio de itaituba/pará. In Anais do Workshop de Informática na Escola, volume 23, page 855.

Sobrinho, H. C. S., Silva, L. C., Castro, A., Oliveira, E. T. H., and Gadelha, B. F. (2016). Organizando o conhecimento sobre técnicas de aprendizagem colaborativas. In de Chile, U., editor, XXI Congresso Internacional de Informática Educativa, volume 12 of Nuevas Ideas en Informática Educativa, pages 152 - 156.

Sullivan, K., Marshall, K., and Tangney, B. (2015). Learning circles: A collaborative technology-mediated peer-teaching workshop. Journal of Information Technology Education: Innovations in Practice, 14:63-83.

Torres, P. L. and Irala, E. A. F. (2014). Aprendizagem colaborativa: teoria e prática. Complexidade: redes e conexões na produção do conhecimento. Curitiba: Senar, pages 61-93.

Vygotsky, L. S. (1980). Mind in society: The development of higher psychological processes. Harvard university press. 